Published in final edited form as:

Eur J Pediatr. 2011 June ; 170(6): 681-688. doi:10.1007/s00431-010-1373-6.

\title{
Clinical practice:
}

\section{Surgical approaches to urolithiasis in children}

\author{
Kathleen Hwang, \\ Department of Urology, Baylor College of Medicine, Houston, TX, USA
}

Matthew D. Mason, and

Department of Urology, University of Virginia, Charlottesville, VA, USA

\section{Craig A. Peters}

Division of Surgical Innovation, Technology and Translation, Children's National Medical Center, Sheik Zayed Institute of Pediatric Surgical Innovation, Washington, DC, USA

Craig A. Peters: crpeters@cnmc.org

\begin{abstract}
The incidence of urolithiasis in children is increasing. Adequate knowledge of treatment modalities and surgical options is therefore essential for every pediatrician. Surgical approaches to urolithiasis in children continue to evolve with advancements in technology and sophistication of current equipment and techniques. Perhaps the most significant development in new techniques is the advent of robotic-assisted laparoscopy. This review, for the general pediatrician, summarizes the most recent pediatric data and guidelines for surgical approaches to treatment of urolithiasis.
\end{abstract}

\section{Keywords}

Urolithiasis; Pediatrics; Surgery; Endoscopy

\section{Introduction}

Pediatric urolithiasis continues to be a problem globally. Inadequately treated stones can contribute to infection, chronic hypertension, and renal failure. In 1989, an estimated one per 1,000 to one per 7,600 pediatric hospital admissions in the USA were attributed to urolithiasis [31]. There is a paucity of epidemiologic data, but the literature demonstrates increasing incidence of this disease [33]. Etiology of stones has significant impact on treatment options and varies widely by geographic location. In developing nations, pediatric urolithiasis is endemic and has typically consisted primarily of bladder stones composed of uric acid. This pattern appears to be changing with increasing development [24]. In European countries, struvite stones (magnesium-ammonium phosphate) are frequent and

\footnotetext{
(C) Springer-Verlag 2010

Correspondence to: Craig A. Peters, crpeters@cnmc.org.

Conflicts of interest There is no conflict of interest.
} 
often coexist with infection and abnormal urinary tract anatomy, while in the USA, calcium stones predominate $[4,26]$.

A wide variety of treatment modalities exist for urinary stone disease, with current options ranging from noninvasive medical therapy to major open surgical approaches. With recent advances in minimally invasive surgical technology and miniaturization of endoscopic equipment, treatment options continue to broaden for pediatric patients.

Factors considered when selecting treatment for urolithiasis include stone size, location, and composition, as well as patient factors such as age and urinary tract anatomy. Imaging of the patient with a presumed stone must define these parameters, as well as an assessment of the upper urinary tract anatomy. While computed tomography (CT) imaging has been the traditional imaging standard, (Fig. 1), the level of radiation exposure has raised concerns as to long-term risks. Whenever possible, ultrasound imaging with judicious use of plain imaging can often provide adequate preoperative information (Figs. 2 and 3). The ideal goal of treatment is to provide stone-free status safely and quickly, while minimizing invasiveness and anesthesia time. Nonsurgical treatment in children is effective for certain types of stones even in the acute setting [14], but surgical therapy is often required for refractory or large stones. Regarding surgical treatment, many studies have demonstrated the safety and efficacy of the various treatment modalities, even in infants [29, 34]. However, there is currently a paucity of evidence-based data relating to selection of individual surgical techniques.

\section{Indications for surgery}

While the dramatic presentation of incapacitating flank pain and hematuria associated with passage of a stone is seen more commonly in adults, children present with more subtle findings, and presenting symptoms of urolithiasis in children vary with age. Children may present with nausea, vomiting, or even fever without overt pain, and symptoms of urolithiasis in children vary with presenting age. Pain from urinary calculi in infants may present as a urinary tract infection, gross or microscopic hematuria, and even nonspecific pain that may mimic colic. While hematuria may be present in any age group, it may be encountered in children with hypercalciuria, hyperoxaluria, and other metabolic disorders without obvious urolithiasis [17]. Adolescent patients, however, commonly present with classical renal colic. Fortunately, up to $50 \%$ of children with urinary calculi will pass the stones spontaneously [22].

The moment a child presents with a stone episode, a pediatric urologist should be consulted to join the team to aid in further evaluation and treatment. With advancing technology, surgical management of urolithiasis has dramatically evolved in the past few decades; however, essential characteristics of evaluation have remained relatively stable. Clinically, symptoms often dictate the speed at which surgical intervention is considered. Signs and symptoms suggestive of infection such as fever, an elevated white count, as well as a urinalysis indicative of infection are important indicators as are intractable pain, nausea, and vomiting. The coexistence of stone with possible obstruction and infection can require 
emergent intervention. Other characteristics of the presentation equally as important in evaluation are stone location, laterality, size, and stone composition.

Stone composition influences the effectiveness of lithotripsy whether attempted via percutaneous or extracorporeal approach. The pretreatment knowledge of stone composition allows for a more efficient and appropriate surgical decision algorithm and subsequent treatment. Cystine stones are resistant to extracorporeal shockwave lithotripsy (SWL) treatment and may require a percutaneous or even an open surgical extraction. Uric acid stones and calcium oxalate dihydrate stones are most responsive to SWL, and relatively fragile, while brushite (calcium phosphate), and struvite stones are less responsive to fragmentation $[11,35]$. Uric acid stones are radiolucent on routine radiographic imaging and account for approximately 3-10\% of all calculi [32]. While excretory urography, retrograde pyelography, and ultrasonography were the modalities of choice used to identify these stones as filling defects or hyperechoic foci, more recently, non-contrast enhanced CT has proven to be an excellent modality to evaluate these particular stones [23]. Although the location and size of the stone may not be an absolute indication for surgical intervention, they certainly play a crucial role in choosing which surgical technique to proceed with. The efficacy of each surgical approach and technique varies greatly depending on the location of the stone, particularly when addressing upper vs. lower tract.

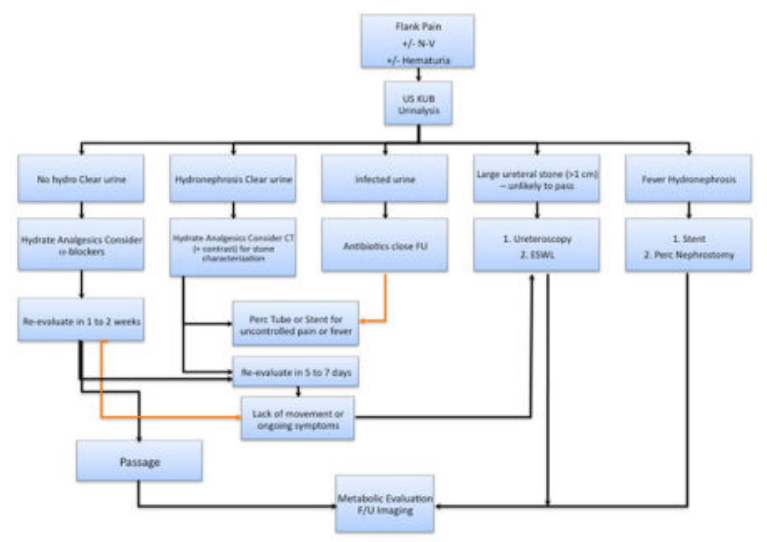

Another consideration is the presence of anatomical confounders, such as special conditions of ureteropelvic junction obstruction and calyceal diverticuli, as well as patients who have undergone previous urological surgeries, such as ureteral reimplantation and urinary diversion. Urolithiasis presenting in a pediatric patient presents a unique challenge, and management must be customized for each individual taking into account the multitude of factors mentioned above.

\section{Surgical options}

Advances in the management of urolithiasis in children were revolutionized by the development of SWL in the early 1980s [7], making it the treatment of choice for most upper tract stones. Although with recent progress in enhancement and modification of modern endoscopic equipment and technique, the options for treatment and subsequent access to the urinary system have expanded. Current options include extracorporeal SWL, 
percutaneous nephrolithotomy (PCNL), ureteroscopy (URS), laparoscopic and roboticassisted pyelolithotomy, as well as more traditional open techniques.

\section{Shock wave lithotripsy}

While there are various types of machines, all models function in the same manner. Each is based on the principle of generating and focusing precise shock wave energy directed at the stone. The stone is subsequently fragmented, and the resulting pieces are passed. To limit stone movement and repeated repositioning, children are usually placed under general anesthesia, except for select older children in whom intravenous sedation may be used. SWL with the Dornier HM3 lithotripter (Dornier Medical Systems, Kennesaw, GA, USA) has been clinically available since the mid 1980s and has successfully been used to treat upper tract stones in children [15] (Fig. 4). Although experience in the pediatric population is limited in comparison, initial series reported complication, stone-free, and safety rates similar to those in adults [19]. Complications are relatively minimal and range in severity from hematuria and ecchymosis to obstruction and sepsis.

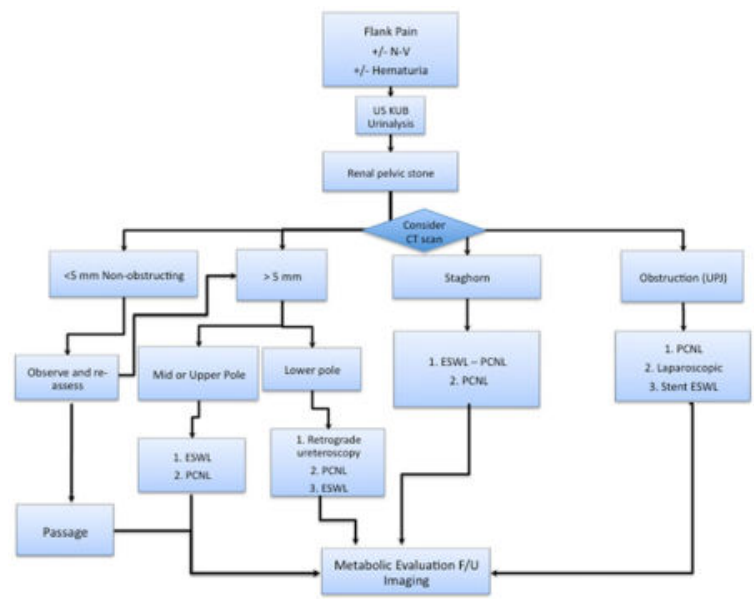

Treatment choices overall are somewhat dictated by the experience of the surgeon. In treating renal stones, important variables including stone burden and renal anatomy are crucial in electing the most effective mode of management, as each factor will change the stone-free rate. There is near unanimity that SWL is currently considered the preferred therapy for small upper tract stones and even stones up to $15 \mathrm{~mm}$ with success rates approaching 75-80\% [2,9]. While stone burden and renal anatomy have been the focus of a multitude of studies, the most effective management for large lower pole stones has yet to be determined. SWL failure and relatively high retreatment rates (40\%) are associated with increased mean stone burden in a few small retrospective studies [20].

Staghorn calculi are those stones that fill the majority of the renal collecting system and are typically made up of struvite stones [28]. While staghorn calculi are fairly rare, they pose a unique challenge to urologists. Traditionally, SWL monotherapy success rates have been dismal in adults; however, the stone-free rates in children are surprisingly much higher. Taking into account the disadvantages of the need for ureteral stenting and multiple 
sessions, SWL monotherapy is considered an acceptable treatment option in children due to the higher stone-free rates ( $80 \%)$ [1] (Figs. 5 and 6).

Treatment of proximal ureteral stones has achieved comparable success rates to renal stones in most pediatric series, though another consideration is the possible requirement of ureteral stenting to aid in localization of the stone as well as stone clearance. Mid to lower ureteral stones should be approached with caution when considering SWL therapy due to the potential for injury to reproductive organs [5], as well as the difficulty in visualization of the stone overlying the pelvic bones.

In a recent review, SWL has proven to be of limited value in children with complex urological conditions when using the more widely available portable lithotripters. Children with no urological conditions experienced a stone-free rate of $67 \%$ in contrast to only $12.5 \%$ in those with pre-existing urological abnormalities [18].

Even without the approval of the Food and Drug Administration (FDA), SWL is considered to be safe and efficacious, and even young children and infants can be treated safely [34].

\section{Ureteroscopy}

Evolution and improvements in the miniaturization of endoscopic equipment along with the usage of the Holmium:YAG laser have enhanced the safety and efficacy of endoscopic treatment in management of urinary stones in children (Figs. 7 and 8). URS is ideally suited for removal or fragmentation of distal ureteral stones. However, it has recently been used for management of small upper tract stones that are resistant to SWL or due to the inability to visualize the stone.

Adoption of techniques used commonly in adults such as use of a ureteral access sheath as well as balloon and sequential coaxial ureteral orifice dilation has made the pediatric ureter and kidney more accessible for endoscopic examination. Although these techniques have engendered caution regarding possible ischemic stricture formation and development of vesicoureteral reflux, the incidence of these sequelae is quite low [27]. With the advent of smaller ureteroscopes and improved optics, ureteral dilation is actually used quite infrequently [12].

Ureteral stenting is an area of contention and controversy. Preoperative ureteral stenting is performed to dilate the ureter temporarily, with a return to the operating room within a few days if initial access to the ureter cannot be done safely. This technique is widely accepted, although it does require an additional anesthetic session; however, postoperative stenting still remains controversial. The decision to place a stent postoperatively is dependent on the experience of the surgeon and other aspects. Factors to consider in making this decision are based on the length of the procedure, number of passes with the instrument, and degree of visible ureteral trauma or edema at the conclusion of the procedure. While stenting may prevent postoperative obstruction, facilitate passage of small residual stones, and aid in the recovery of minor trauma to the ureter, children can experience significant discomfort from the stents. 
Complications, while rare, range from hematuria and urinary tract infections to ureteral perforation and later stricture formation. Simple perforation can be managed easily with a temporary stent. Fortunately, more significant tears and avulsions are rarely encountered. Use of a stent with an extraction string permits an efficient option for temporary drainage without the need for a further anesthetic to remove the stent. This is generally well tolerated in all age groups.

\section{Percutaneous nephrolithotomy}

The introduction of percutaneous techniques in approaching renal stones in the late 1970s revolutionized treatment for large stone burdens. PCNL is performed once access into the collecting system is attained percutaneously, and sequentially dilating the tract over a wire. The stones are removed or fragmented under direct vision through a nephroscope. While technically challenging, the safety and efficacy of PCNL for large renal stones was well established in adults, although it was not until the late 1990s that special instrumentation was adapted for children [13]. PCNL is now an established approach in children with proven safety and efficacy as both monotherapy as well as in combination with SWL.

While there is no current international consensus, relative indications parallel those in adults including large stone burden (>15 mm) and SWL failure (Fig. 3). Stone-free rates range from $68 \%$ up to $95 \%$, with the higher stone-free rates seen in cases with use of multiple tracts as well as a staged approach, where percutaneous access is obtained initially, and then through the mature tract, the stone is fragmented a few days later [3, 25]. Complications include intraoperative bleeding requiring transfusion, injury to pelvicaliceal system, hydrothorax, as well as fever and sepsis.

Historically, lower pole access to the collecting system via a subcostal puncture was viewed as the safest approach. However, when performed by experienced and skilled endourologists, supracostal access to the upper pole of the kidney can be accomplished with a high degree of safety and efficacy [8]. Placement of a postoperative stent or nephrostomy tube varies among series, while subject to the experience of the surgeon and patient.

\section{Laparoscopic and robotic-assisted pyelolithotomy}

With continued advancements and sophistication in instrumentation and techniques, the role of laparoscopy in the treatment of urolithiasis in children continues to evolve. Specific scenarios where laparoscopy and robotic-assisted laparoscopy have been used successfully in adults are during concomitant treatment of ureteropelvic junction obstruction and primary treatment of large calculi. Only recently, this approach has been explored in children. Successful transperitoneal laparoscopic pyelolithotomy has been described in eight children who previously failed PCNL with no noted major complications [6].

Although laparoscopic stone removal and concomitant pyeloplasty for ureteropelvic junction obstruction have been reported in a number of series in adults, experience in children still remains relatively new. Lee et al. described their initial experience of robotic-assisted laparoscopic pyelolithotomy with five procedures consisting of four patients with refractory cystine staghorn calculi and one child with concurrent ureteropelvic junction obstruction [16]. Four of these procedures were completed robotically with one case requiring 
conversion to an open procedure. Further studies are needed to determine if shorter operative times are achievable and if these procedures can be completed safely in children.

\section{Open surgical management of urolithiasis}

Surgical management of urolithiasis in children has evolved dramatically over the past few decades. While a substantial proportion of pediatric patients are not amenable to endoscopic or shockwave therapy, particularly in patients with anatomic considerations, with the advent of minimally invasive modalities, the need for open approaches has decreased [21]. With technological advancement, the necessity of open surgical management has become increasingly rare.

While bladder calculi are unusual in the industrialized country, they are most often encountered in bladders with anatomic or functional abnormalities as well as in children with underlying metabolic abnormalities. Bladder calculi are often large and had previously required open surgical removal via a suprapubic cystolithotomy. However, as technology evolves, even bladder calculi are now being treated with minimally invasive techniques [10]. Endoscopic treatment of bladder calculi is possible; however, controversy of this approach exists when following lower urinary tract reconstruction. Currently, open surgical approaches for treatment of upper tract urolithiasis are used even less frequently than in cases involving the lower urinary tract.

\section{Conclusion}

Urolithiasis in children is of diverse etiology requiring carefully planned, customized diagnostic and management strategies. Research continues to better define the risk factors for developing stone disease, as does the improvement in diagnostic capability. With current technical sophistication in SWL, endoscopic, as well as percutaneous and laparoscopic techniques, the reality of a safe, effective, and minimally invasive treatment for all cases of urolithiasis is becoming more attainable.

\section{Acknowledgments}

This study was supported in part by the 1K12DK083014 Multidisciplinary K12 Urology Research Career Development Program at Baylor to KH from the National Institute of Kidney and Digestive Diseases.

\section{Abbreviations}

ESWL Extracorporeal shockwave lithotripsy

PCNL Percutaneous nephrolithotomy

URS Ureteroscopy

US Ultrasonography

KUB Kidney ureter bladder

N-V Nausea and vomiting 


\section{References}

1. Al-Busaidy SS, Prem AR, Medhat M. Pediatric staghorn calculi: the role of extracorporeal shock wave lithotripsy monotherapy with special reference to ureteral stenting. J Urol. 2003; 169(2):629_ 633.10.1097/01.ju.0000047231.36474.57 [PubMed: 12544330]

2. Ather MH, Noor MA. Does size and site matter for renal stones up to $30-\mathrm{mm}$ in size in children treated by extracorporeal lithotripsy? Urology. 2003; 61(1):212-215. S0090429502021283. discussion 215. [PubMed: 12559298]

3. Badawy H, Salama A, Eissa M, et al. Percutaneous management of renal calculi: experience with percutaneous nephrolithotomy in 60 children. J Urol. 1999; 162(5):1710-1713. S0022-5347(05)68220-1. [PubMed: 10524919]

4. Bartosh SM. Medical management of pediatric stone disease. Urol Clin North Am. 2004; 31(3): 575-587. x-xi.10.1016/j.ucl.2004.04.005 [PubMed: 15313066]

5. Basar MM, Samli MM, Erbil M, et al. Early effects of extracorporeal shock-wave lithotripsy exposure on testicular sperm morphology. Scand J Urol Nephrol. 2004; 38(1):3841.10.1080/00365590310015723 [PubMed: 15204425]

6. Casale P, Grady RW, Joyner BD, et al. Transperitoneal laparoscopic pyelolithotomy after failed percutaneous access in the pediatric patient. J Urol. 2004; 172(2):680-683. S0022-5347(05)61716-8. discussion 683. [PubMed: 15247760]

7. Chaussy C, Schmiedt E, Jocham D, et al. First clinical experience with extracorporeally induced destruction of kidney stones by shock waves. J Urol. 1982; 127(3):417-420. [PubMed: 6977650]

8. El-Nahas AR, Shokeir AA, El-Kenawy MR, et al. Safety and efficacy of supracostal percutaneous nephrolithotomy in pediatric patients. J Urol. 2008; 180(2):676-680. S0022-5347(08)00993-2. [PubMed: 18554648]

9. Elsobky E, Sheir KZ, Madbouly K, Mokhtar AA. Extracorporeal shock wave lithotripsy in children: experience using two second-generation lithotripters. BJU Int. 2000; 86(7):851-856. [PubMed: 11069413]

10. Fragoso AC, Valla JS, Steyaert H, et al. Minimal access surgery in the management of pediatric urolithiasis. J Pediatr Urol. 2009; 5(1):42-46. S1477-5131(08)00354-9. [PubMed: 18805739]

11. Fuchs G, Miller K, Rassweiler J, Eisenberger F. Extracorporeal shock-wave lithotripsy: one-year experience with the Dornier lithotripter. Eur Urol. 1985; 11(3):145-149. [PubMed: 4029228]

12. Herndon CD, Viamonte L, Joseph DB. Ureteroscopy in children: is there a need for ureteral dilation and postoperative stenting? J Pediatr Urol. 2006; 2(4):290-293. S1477-5131(06)00017-9. [PubMed: 18947623]

13. Jackman SV, Docimo SG, Cadeddu JA, et al. The "mini-perc" technique: a less invasive alternative to percutaneous nephrolithotomy. World J Urol. 1998; 16(6):371-374. [PubMed: 9870281]

14. Kaya M, Boleken ME, Soran M, et al. Acute renal failure due to bilateral uric acid lithiasis in infants. Urol Res. 2007; 35(3):119-122.10.1007/s00240-007-0088-2 [PubMed: 17396250]

15. Kramolowsky EV, Willoughby BL, Loening SA. Extracorporeal shock wave lithotripsy in children. J Urol. 1987; 137(5):939-941. [PubMed: 3573189]

16. Lee RS, Passerotti CC, Cendron M, et al. Early results of robot assisted laparoscopic lithotomy in adolescents. J Urol. 2007; 177 (6):2306-2309. S0022-5347(07)00316-3. discussion 2309-2310. [PubMed: 17509345]

17. Milliner DS, Murphy ME. Urolithiasis in pediatric patients. Mayo Clin Proc. 1993; 68(3):241-248. [PubMed: 8474265]

18. Nelson CP, Diamond DA, Cendron M, et al. Extracorporeal shock wave lithotripsy in pediatric patients using a late generation portable lithotriptor: experience at Children's Hospital Boston. J Urol. 2008; 180(4 Suppl):1865-1868. S0022-5347(08)01335-9. [PubMed: 18721967]

19. Newman DM, Coury T, Lingeman JE, et al. Extracorporeal shock wave lithotripsy experience in children. J Urol. 1986; 136(1 Pt 2):238-240. [PubMed: 3723671]

20. Onal B, Demirkesen O, Tansu N, et al. The impact of caliceal pelvic anatomy on stone clearance after shock wave lithotripsy for pediatric lower pole stones. J Urol. 2004; 172(3):1082-1086. S0022-5347(05)61567-4. [PubMed: 15311043] 
21. Paik ML, Wainstein MA, Spirnak JP, et al. Current indications for open stone surgery in the treatment of renal and ureteral calculi. J Urol. 1998; 159(2):374-378. S0022-5347(01)63922-3. discussion 378-379. [PubMed: 9649242]

22. Pietrow PK, Jct P, Adams MC, et al. Clinical outcome of pediatric stone disease. J Urol. 2002; 167(2 Pt 1):670-673. [PubMed: 11792950]

23. Resnick MI, Kursh ED, Cohen AM. Use of computerized tomography in the delineation of uric acid calculi. J Urol. 1984; 131 (1):9-10. [PubMed: 6690755]

24. Rizvi SA, Naqvi SA, Hussain Z, et al. Pediatric urolithiasis: developing nation perspectives. J Urol. 2002; 168(4 Pt 1):1522-1525.10.1097/01.ju.0000028601.63446.51 [PubMed: 12352448]

25. Salah MA, Toth C, Khan AM, Holman E. Percutaneous nephrolithotomy in children: experience with 138 cases in a developing country. World J Urol. 2004; 22(4):277-280.10.1007/ s00345-004-0454-4 [PubMed: 15448997]

26. Sarica K. Pediatric urolithiasis: etiology, specific pathogenesis and medical treatment. Urol Res. 2006; 34(2):96-101.10.1007/s00240-005-0018-0 [PubMed: 16432692]

27. Schuster TG, Russell KY, Bloom DA, et al. Ureteroscopy for the treatment of urolithiasis in children. J Urol. 2002; 167(4):1813. S0022-5347(05)65237-8. discussion 1815-1816. [PubMed: 11912438]

28. Segura JW, Preminger GM, Assimos DG, et al. Nephrolithiasis Clinical Guidelines Panel summary report on the management of staghorn calculi. The American Urological Association Nephrolithiasis Clinical Guidelines Panel. J Urol. 1994; 151(6):1648-1651. [PubMed: 8189589]

29. Smaldone MC, Cannon GM Jr, Wu HY, et al. Is ureteroscopy first line treatment for pediatric stone disease? J Urol. 2007; 178(5):2128-2131. S0022-5347(07)01786-7. discussion 2131. [PubMed: 17870124]

30. Smaldone MC, Corcoran AT, et al. Endourological management of pediatric stone disease: present status. J Urol. 2009; 181(1):17-28. [PubMed: 19012920]

31. Stapleton FB. Nephrolithiasis in children. Pediatr Rev. 1989; 11 (1):21-30. [PubMed: 2664747]

32. Steele BT, Lowe P, Rance CP, et al. Urinary tract calculi in children. Int J Pediatr Nephrol. 1983; 4(1):47-52. [PubMed: 6853041]

33. Van Dervoort K, Wiesen J, Frank R, et al. Urolithiasis in pediatric patients: a single center study of incidence, clinical presentation and outcome. J Urol. 2007; 177(6):2300-2305. S0022-5347(07)00318-7. [PubMed: 17509344]

34. Wadhwa P, Aron M, Bal CS, et al. Critical prospective appraisal of renal morphology and function in children undergoing shockwave lithotripsy and percutaneous nephrolithotomy. J Endourol. 2007; 21(9):961-966.10.1089/end.2006.9928 [PubMed: 17941769]

35. Wu HY, Docimo SG. Surgical management of children with urolithiasis. Urol Clin North Am. 2004; 31(3):589-594. xi.10.1016/j.ucl.2004.04.002 [PubMed: 15313067] 


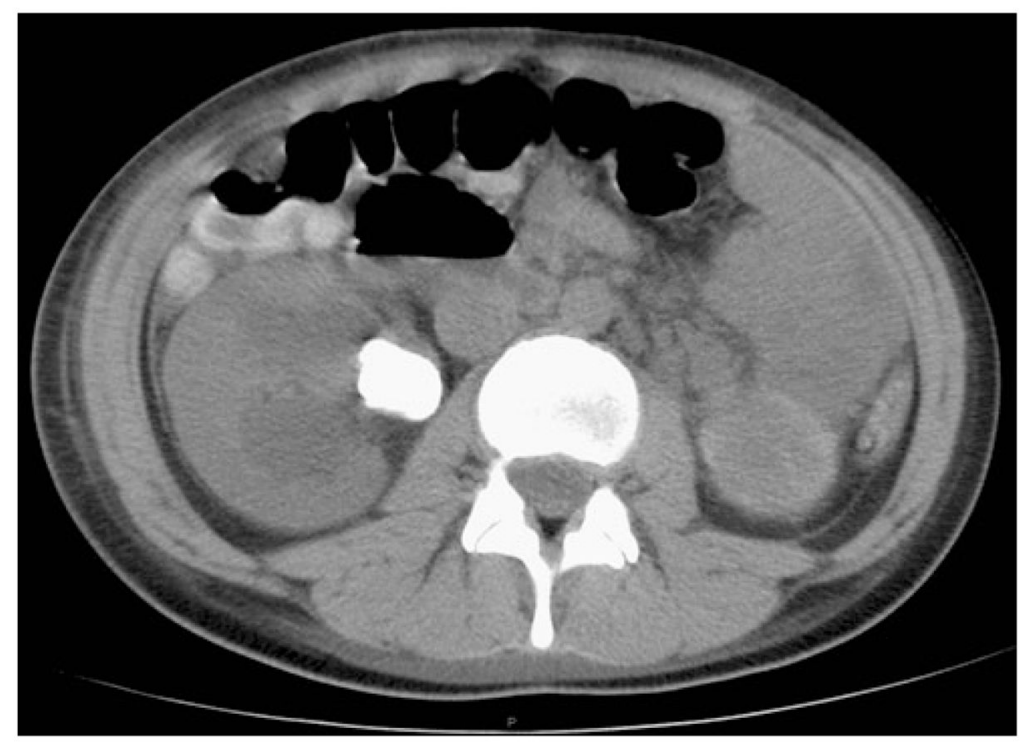

Fig. 1.

Computed tomography axial image of $2.5 \mathrm{~cm}$ right ureteropelvic junction stone causing hydronephrosis in 16 -year-old female 


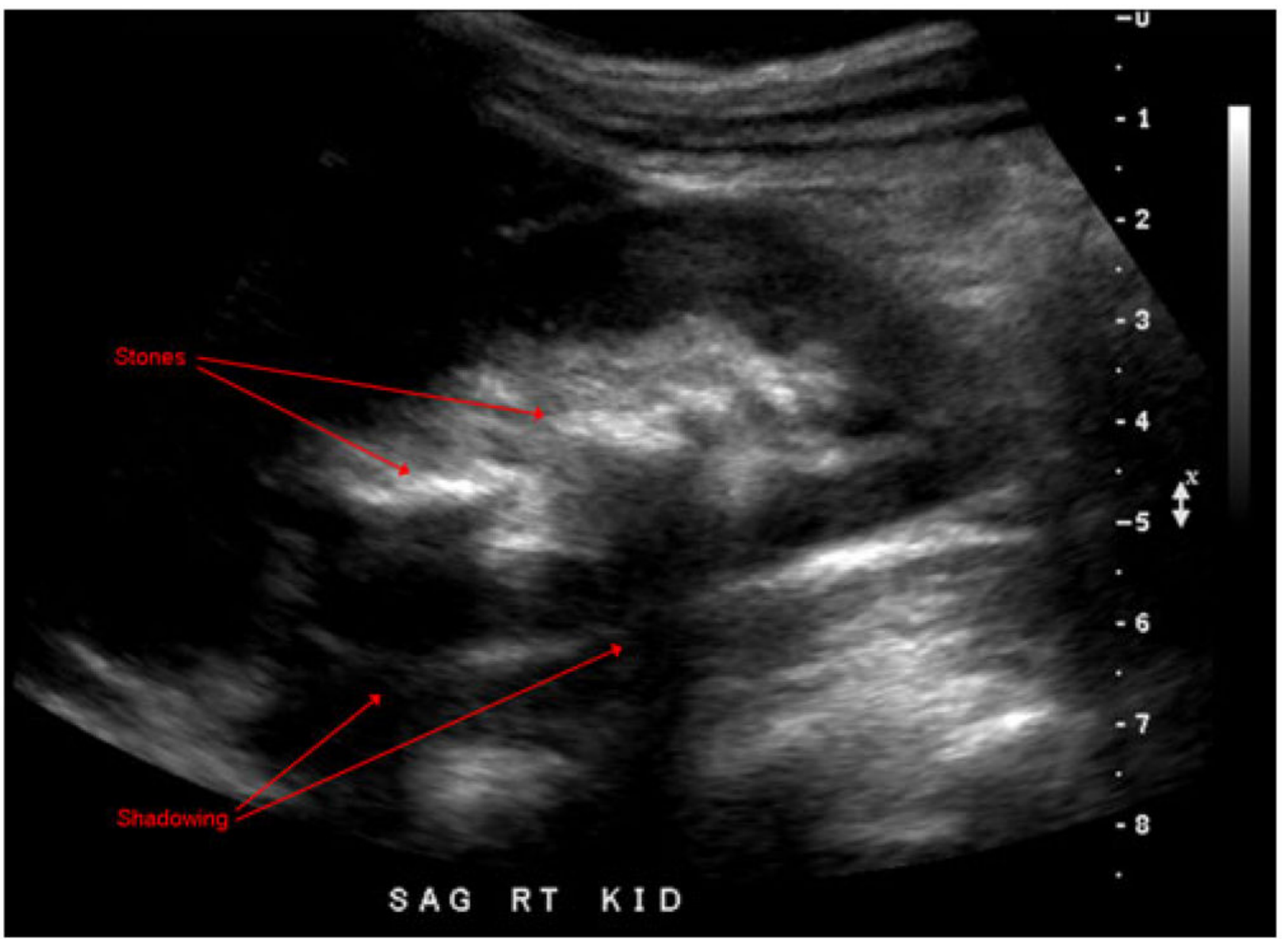

Fig. 2.

Ultrasound image of a staghorn renal calculus in 6-year-old female. In this sagittally oriented image, multiple sections of this stone can be seen, appearing as hyperechoic areas with posterior shadowing. No dilation of the renal collecting system is present. Ultrasound can underestimate the size of the stone due to inadequate penetration through the stone of the sound waves 


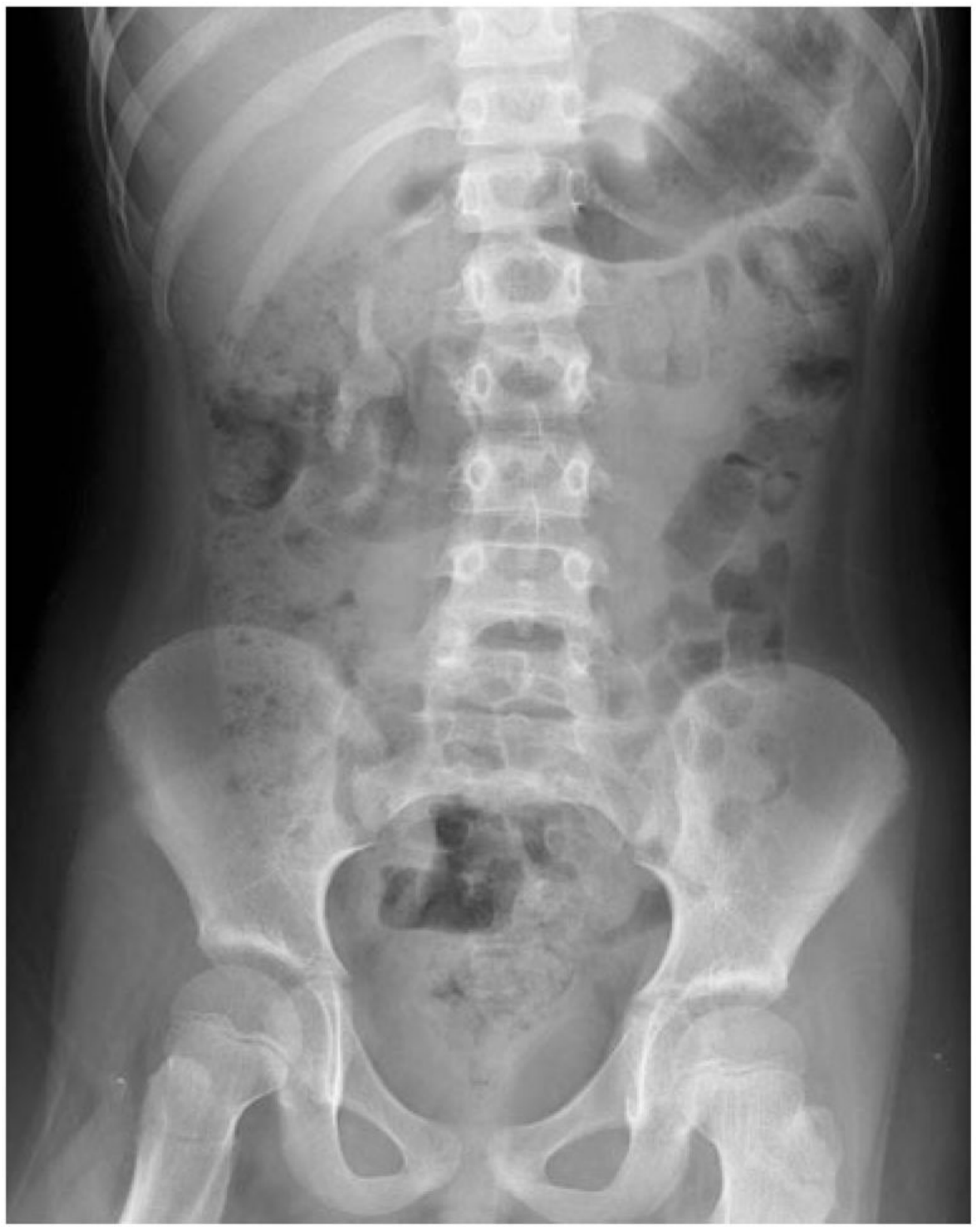

Fig. 3.

Plain film X-ray (KUB) of staghorn renal calculus shown in Fig. 2. Right-sided radio-opaque stone measures approximately $5 \times 2$ $\mathrm{cm}$ and fills the majority of the collecting system 


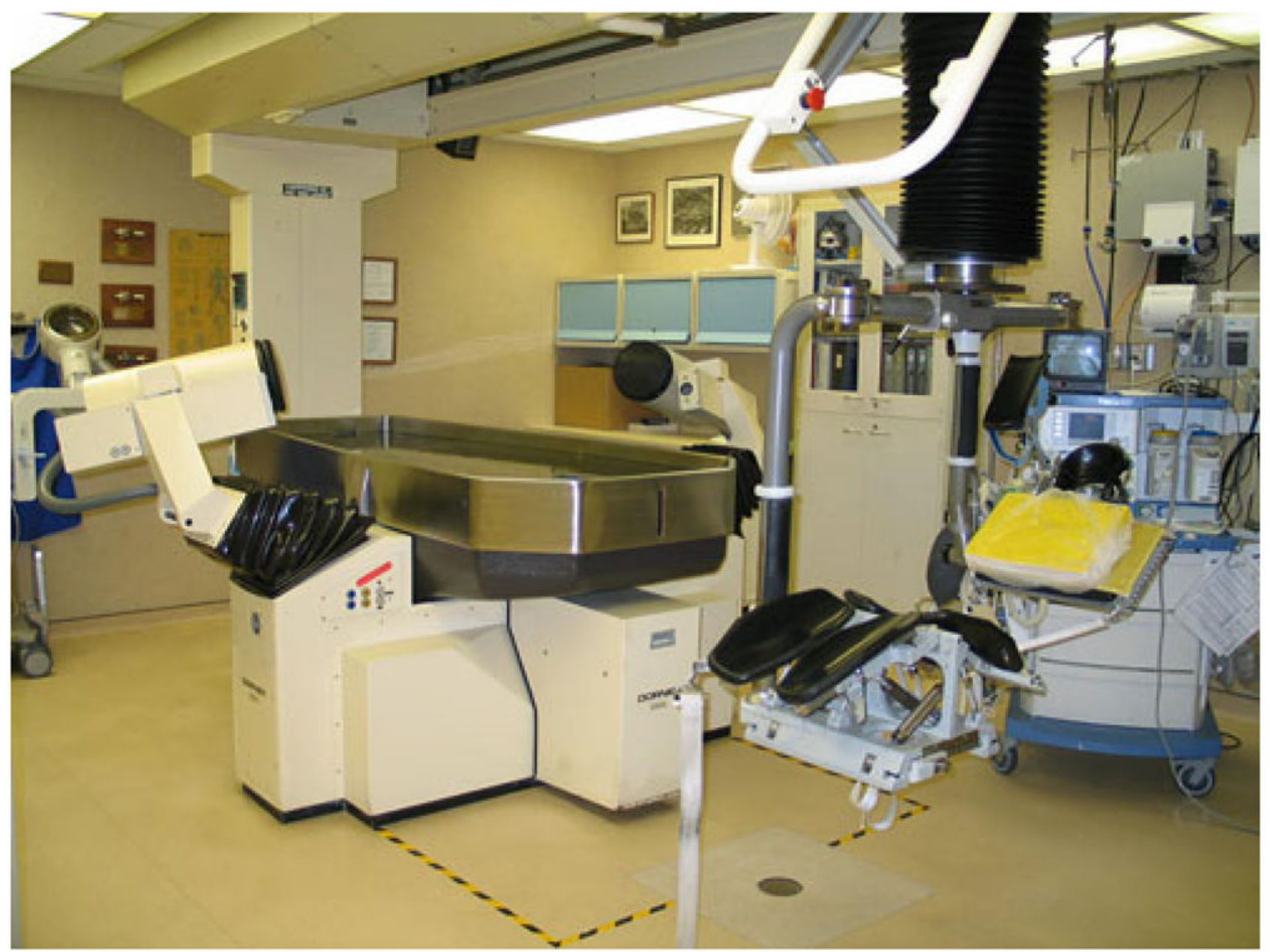

Fig. 4.

Dornier HM3 lithotripter for extracorporeal lithotripsy. The patient under anesthesia is partially submerged in a water bath that facilitates energy transfer of the sound waves focused on the stone using fluoroscopic monitoring 


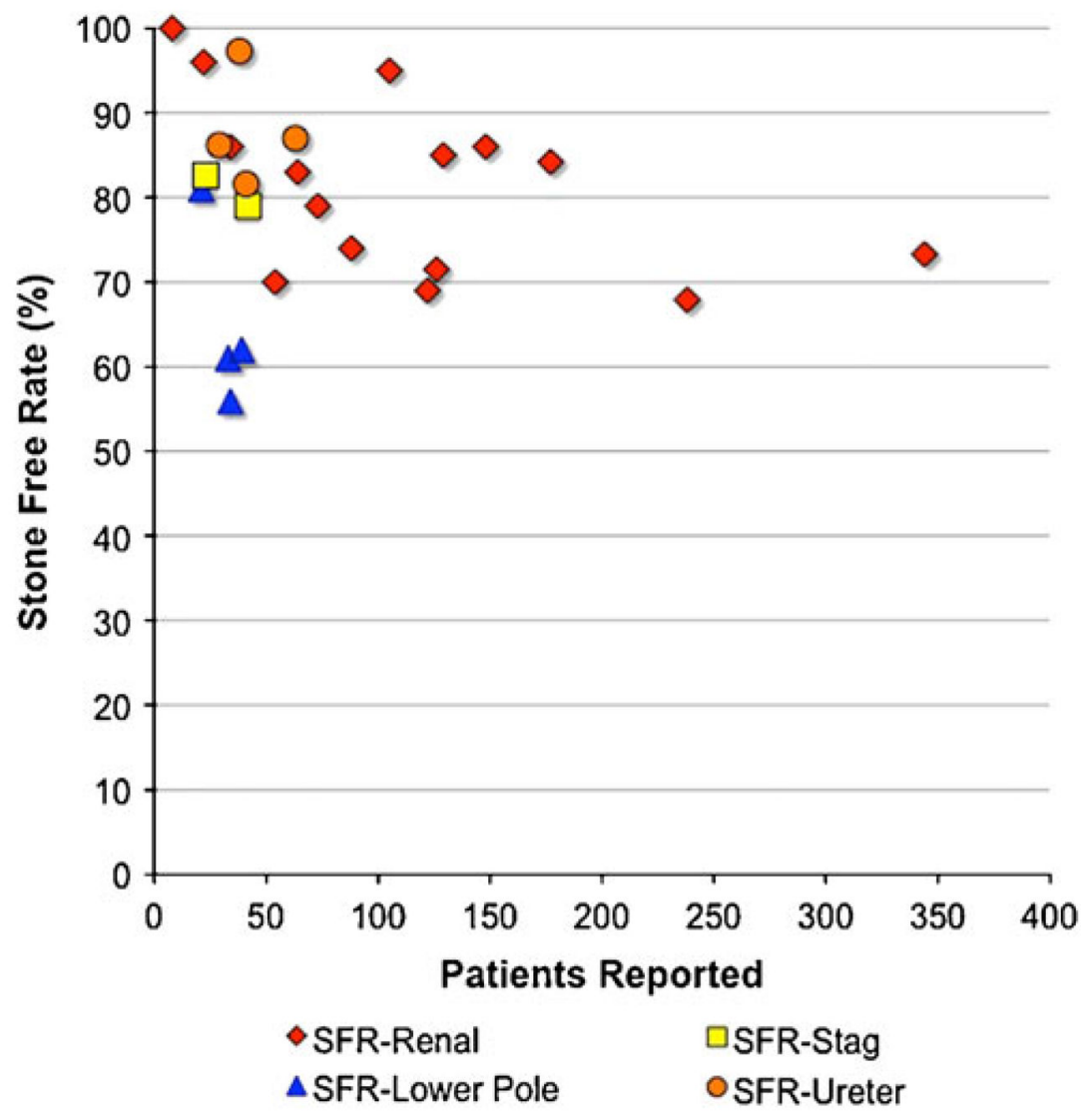

Fig. 5.

Pediatric ESWL stone-free rates based on size of the studies and location of the stones. Clearance of lower pole stones is significantly less efficient than other locations. Adapted from Smaldone et al., [30] 


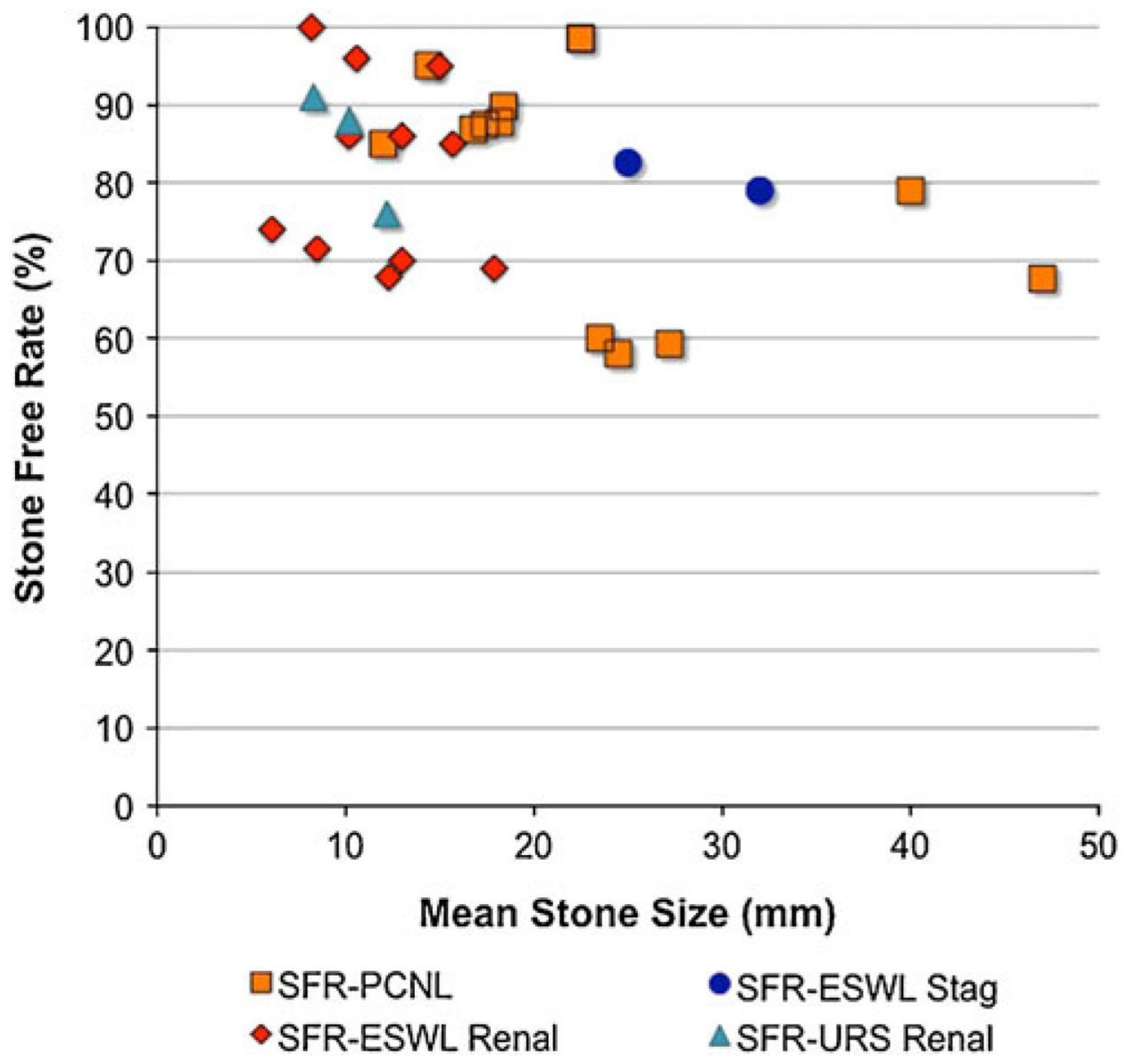

Fig. 6.

Stone-free rates in children following PCNL and ESWL. Adapted from Smaldone et al., [30] 


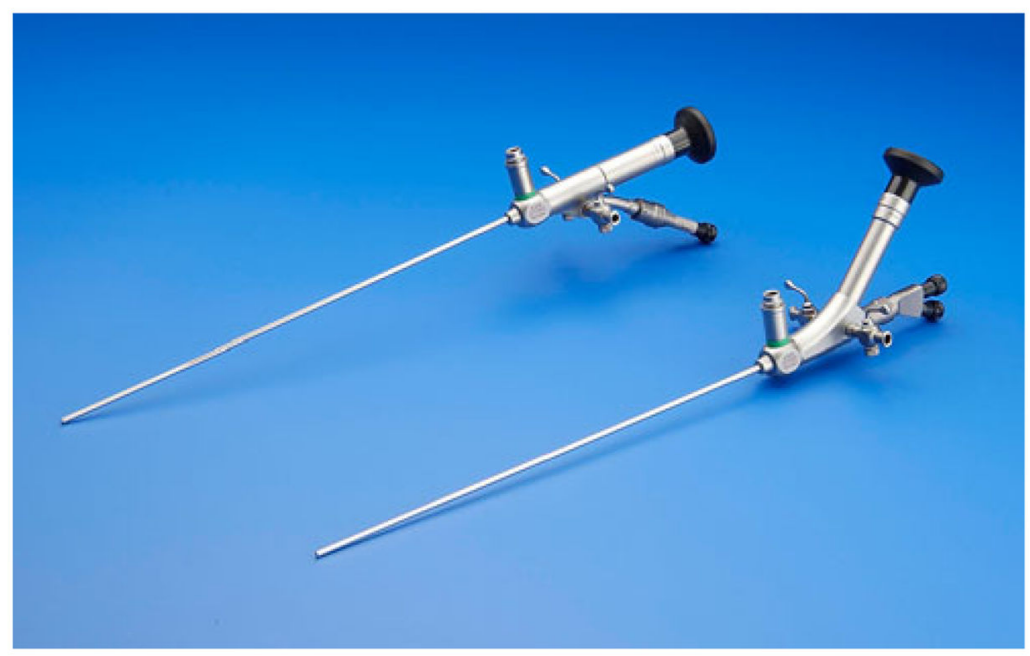

Fig. 7.

Rigid ureteroscopes with the smallest caliber at 4.5-Fr are useful for distal ureteral stones, but can reach into the proximal ureter safely. @2009 Photo Courtesy of KARL STORZ Endoscopy-America, Inc 


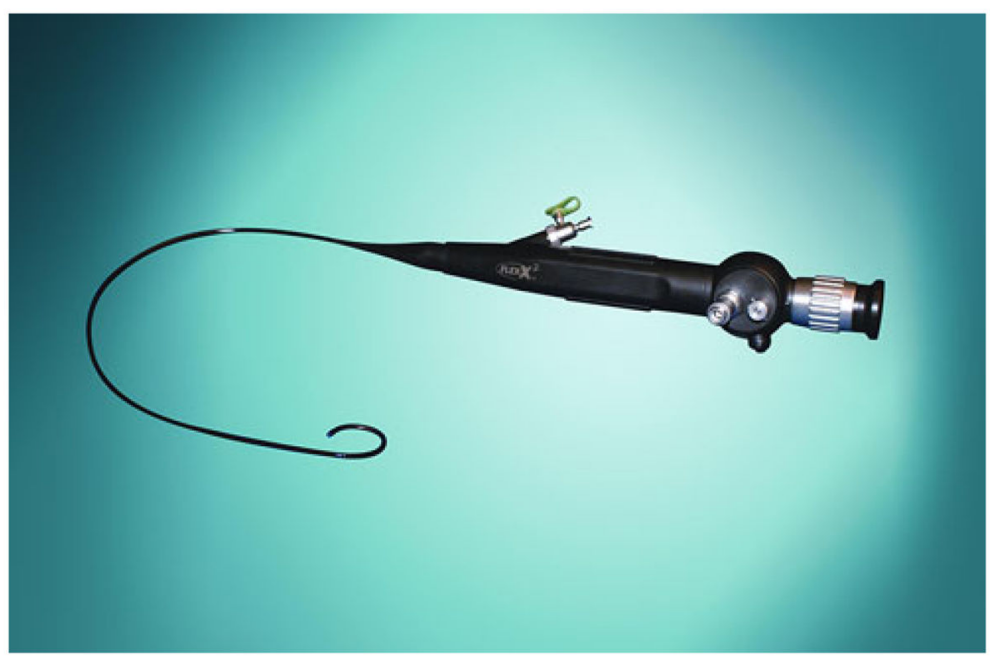

Fig. 8.

Flexible ureteroscope that is particularly useful for access to the kidney using a retrograde approach. (C2009 Photo Courtesy of KARL STORZ Endoscopy-America, Inc 